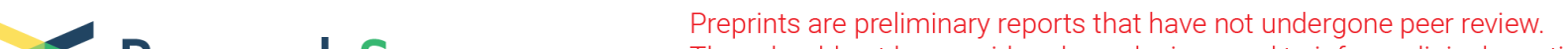 $\begin{array}{ll}\text { Research Square } & \begin{array}{l}\text { They should not be considered conclusive, used to inform clinical practice, } \\ \text { or referenced by the media as validated information. }\end{array}\end{array}$
}

\section{A Comparative Study of the Recent Most Potent Small-Molecule PD-L1 Inhibitors: What Can We Learn?}

\section{Yu Zhang}

Zhejiang University College of Pharmaceutical Sciences

\section{Yu Guo}

Zhejiang University College of Pharmaceutical Sciences

Jian Gao

Zhejiang University College of Pharmaceutical Sciences

\section{Wenhai Huang}

Hangzhou Medical College

\section{Xiaowu Dong}

Zhejiang University College of Pharmaceutical Sciences

\section{Mei Liu (D2020020041@hmc.edu.cn )}

Zhejiang Provincial People's Hospital, People's Hospital of Hangzhou Medical College https://orcid.org/0000-0003-0540-7566

\section{Research Article}

Keywords: Cancer immunotherapy, PD-1/PD-L1, Small molecule inhibitors, Immune checkpoint inhibitors

Posted Date: February 19th, 2021

DOl: https://doi.org/10.21203/rs.3.rs-212119/v1

License: (c) (i) This work is licensed under a Creative Commons Attribution 4.0 International License. Read Full License

Version of Record: A version of this preprint was published at Medicinal Chemistry Research on April 13th, 2021. See the published version at https://doi.org/10.1007/s00044-021-02728-3. 


\section{Abstract}

Immune checkpoint inhibitors targeting the PD-1/PD-L1 pathway have become a "game-changer" in the cancer treatment. However, none of the small molecular inhibitors has been approved yet. To explore the advantages and disadvantages of various scaffolds, different biological evaluations were performed on the three selected small inhibitors, namely Incyte-001, Incyte-011, and BMS-1001. In the HTRF assay, BMS-1001 showed the best binding activity for PD-L1 $\left(I_{50}=0.9 \mathrm{nM}\right)$ while Incyte-011 $\left(\mathrm{IC}_{50}=5.293 \mathrm{nM}\right)$ was twice more potent than the Incyte-001 $\left(\mathrm{IC}_{50}=11 \mathrm{nM}\right)$. Also, only Incyte-011 increased the IFN- $\gamma$ production. Notably, the Incyte-001 exhibited the high-est cytotoxicity $\left(\mathrm{EC}_{50}=1.635 \mu \mathrm{M}\right)$. Interestingly, Incyte-001 (injected intravenously $2 \mathrm{mg} / \mathrm{kg}$ ) also displayed good blood-brain barrier permeability and reached a high concentration in the brain tissue. Finally, molecular docking and modeling studies suggested that the compounds bind in a pocket at the interface of two PD-L1 monomers. Overall, our work shows that PD-1/PD-L1 small molecular inhibitors have different biological characteristics depending on their unique skeletons, which can be further improved to better their clinical application.

\section{Introduction}

Immunotherapy is an emerging approach for oncological treatment [1]. Especially, the immune checkpoint inhibitors (ICls) that target the PD-1/PD-L1 pathway get a lot of attention and have shown great improvement in the treatment of several tumors [2-4].

Programmed cell death 1 (PD-1), an important immunosuppressive molecule, is expressed on various immune cells, including T cells, B cells, tumor-associated macro-phages (TAMs), and natural killer cells (NK cells) $[5,6]$. In the tumor cells, overexpres-sion of PD-L1 induces the PD-1/PD-L1 pathway which inhibits $T$ cell mediated anti-tumor immune response, and thereby facilitate the survival of tumor cells [7, 8]. Therefore, the ICls have become one of the most promising agents in cancer therapy.

Notably, the monoclonal antibodies (mAbs) of PD-1/PD-L1 inhibitors have shown significant clinical effectiveness in various tumors including melanoma, lung cancer, Hodgkin lymphoma, urothelial carcinoma, bladder cancer, colorectal cancer, renal cell carcinoma, and glioblastoma [9-12]. And these monoclonal antibodies showing their advantages, also have several disadvantages such as lack of oral bioavailability, pro-longed half-life, poor permeability, immune-related adverse effects (irAEs), and relatively lower clinical response in brain tumors [13-15]. However, these shortcomings can be overcome by developing small molecular inhibitors.

Recently, a series of small molecular inhibitors, including macrocyclic peptides, peptide mimetics, and non-peptide small molecular inhibitors, have been discovered for improvement of treatment [16-19]. Among them, small molecules discovered by Bristol-Myers Squibb (BMS) exhibit activity in the nanomolar range. Their skeletons have a biphenyl group connected to a substituted aromatic ring by a benzyl ether bond. Shortly, other companies including Incyte, Gilead, and etc., also disclosed similar compounds, including a series of C2 symmetrical skeleton compounds. Interestingly, through the HTRF 
(Homogeneous Time-Resolved Fluorescence) assay and cell-based co-culture PD-1 signaling assay, C2 symmetrical skeleton compounds with di-mer-structure are revealed to be more effective than the monomers [20]. However, the reason remains unknown. And their toxicity and druggability still need to be evaluated. Furthermore, unlike monoclonal antibodies, these small molecular inhibitors may have the potent for crossing the blood-brain barrier (BBB) and for the treatment of central neural system (CNS) tumors. Therefore, it is vital to evaluate their blood-brain barrier (BBB) penetrability and distribution in the brain.

Here, we have conducted several biological evaluations and performed modeling methods to estimate the inhibitory effects of distinct molecules that target the PD-1/PD-L1 pathway. The monomer 001 (Incyte001) and dimer compounds 011 (In-cyte-011) from Incyte, reported for great activity in the patents, were selected as rep-resentative for which no other exact experimental data is available. For the same rea-son, BMS-1001 was selected from many patents by BMS in this research (Scheme 1). Their abilities to block the binding of PD-1/PD-L1 were verified by using the ELISA as-say. And the cytotoxicity profiles were detected in A549 cells. Meanwhile, we also evaluated their abilities to penetrate the brain-blood barrier (BBB) and distribution in the brain. Finally, using computer-aided drug design (CADD), we analyzed the related amino acid residues that interact with compounds.

\section{Results And Discussion}

\subsection{Chemistry}

The synthesis of Incyte-001 is shown in Scheme 2 [21]. Starting with commercially available 2-amino-6bromobenzonitrile 1, Suzuki coupling reaction with phenyl-boronic acid produced biphenylnitrile product 2. The resulting compound was treated with O-(7-Azabenzotriazol-1-yl)-N,N,N',N'-tetramethyluronium hexafluorophosphate (HATU) and coupled with 5-bromopicolinic acid 3 to provide bromopicolinamide intermediate 4. Then, this was reacted with pinacol vinyl boronate in the presence of palladium catalyst to obtain vinylpicolinamide compound 5 . Next, using $\mathrm{K}_{2} \mathrm{OsO}_{4} / \mathrm{NaIO}_{4}$, classical oxidative cleavage of double bond in the compound 5 resulted in formylpicolinamide 6 . Lastly, reductive amination with ethanolamine produced the final product Incyte-001

The synthesis of Incyte-011 is shown in Scheme 3 [22]. Pinacol boronation of commercially available 3bromo-2-methylaniline 7 with bis(pinacolato)diboron under standard condition produced arylboronate 8 in good yield, which was subsequently Suzuki coupled with 3-bromo-2-chloroaniline 9 . The resulting biphenyl-diamine in-termediate 10 was treated with HATU and coupled with 5-bromopicolinic acid 3 to obtain compound 11 with $58 \%$ yield. Compound 11 , reacted with pinacol vinyl-boronate and catalyzed with tetrakis(triphenylphosphine) palladium, produced dienes compound 12 in good yield. Then, the oxidative cleavage of the dienes intermediate 12 with $\mathrm{K}_{2} \mathrm{OsO}_{4} / \mathrm{NaIO}_{4}$ provided an aldehyde intermediate 13 in mild yield. Finally, re-ductive amination with ethanolamine yielded the desired product Incyte- 011 . 
The synthesis of BMS-1001 is shown in Scheme 4 [23]. Starting from commercially available 3-Bromo-2methylbenzoic acid 14, reduction reaction with $\mathrm{BH}_{3}$-THF produced (3-bromo-2-methylphenyl)methanol product 15, which was coupled with (2,3-dihydrobenzo[b][I,4]dioxin-6-yl)boronic acid to obtain intermediate 16 . Then, the intermediate 16 was reacted with 2,4-dihydroxy-5-methylbenzaldehyde (Mitsunobu Reaction) to obtain the compound 17 which upon reductive amination with Serine produced the final product BMS-1001.

\subsection{Homogeneous Time Resolved Fluorescence (HTRF)}

The PD-1/PD-L1 blocking abilities of the compounds were estimated using the HTRF assay. We found that both compounds from Incyte Inc. showed great activities within the nanomolar range. $\mathrm{Th}^{\mathrm{IC}} \mathrm{I}_{50}$ values of the compound 001 and 011 were $11 \mathrm{nM}$ and $5.293 \mathrm{nM}$, respectively. This suggested that compound 011 is almost twice potent than the compound 001. And the result is consistent with a previous report [20]. More interestingly, BMS-1001 displayed the best result with an $\mathrm{IC}_{50}$ value of $0.9 \mathrm{nM}$ in our study, which is worth exploring furthermore (Fig. 1).

\subsection{In vitro estimation of IFN-Y secretion levels}

Many studies showed that blockade of the PD-1/PD-L1 interaction could re-activate T cell function such as the secretion of IFN- $\gamma$, which suggested the inhibi-tion of immune escape in the tumor cells [24]. Thus, an in vitro $T$ cell co-culture assay was performed to assess the $T$ cell activation effect of selected compounds (Fig. 2). Treatment with Incyte-011 increased the production of IFN- $y$ in a dose-dependent manner. And the level of IFN- $\gamma$ had reached to $200 \mathrm{pg} / \mathrm{mL}$ at the maximum dose $(1 \mu \mathrm{M})$ of Incyte- 011 . However, the compound Incyte-001 and BMS-1001 had failed to affect IFN-y production significantly. Obviously, Incyte-011 was more potent in blocking the PD-1/PD-L1 interactions, compared with the monomer molecular Incyte-001. For BMS-1001, the different chemical skeleton could be the reason for such an outcome.

\subsection{Evaluation of cytotoxicity}

To evaluate the cytotoxicity of the compounds, the survival assay was performed in A549 tumor cells. Up to $10 \mu \mathrm{M}$, Incyte-011 and BMS-1001 exhibited no significant cytotoxicity. However, at $10 \mu \mathrm{M}$, Incyte-001 decreased the cell survival rate to $70 \%$, showing more obvious cytotoxicity than the other two compounds. The $\mathrm{EC}_{50}$ value of Incyte-001was $1.635 \mu \mathrm{M}$ (Fig. 3).

\subsection{Brain and blood distribution of compounds in mice}

As described above, Incyte-001, Incyte-011, and BMS-1001 showed promising PD-1/PD-L1 blockade in vitro. Next, the pharmacokinetic (PK) properties and brain-blood barrier (BBB) permeability of the three compounds were assessed. The corresponding distribution parameters are summarized in Fig. 4. After iv admin-istration ( $2 \mathrm{mg} / \mathrm{kg}, \mathrm{n}=3$ ), BMS-1001 showed a plasma Cmax of $5600 \mathrm{ng} / \mathrm{mL}$ at around $0.08 \mathrm{~h}$, indicating a moderate systematic exposure. However, the immeasurable con-centration in brain showed BMS-1001 had no ability to cross the BBB. It seems that the amino acid chain of BMS-1001 led to a poor PK profile and decreased its concentration by enhancing metabolism in the body. For Incyte-011, the 
plasma Cmax values was nearly $400 \mathrm{ng} / \mathrm{mL}$, which was higher than the brain concentration. This suggested that Incyte-011 had poor pharmaco-kinetic properties. Interestingly, though the plasma Cmax of Incyte-001 was low, it exhibited the highest Cmax value of $4000 \mathrm{ng} / \mathrm{mL}$ in the brain compared to the other two compounds. This suggested that Incyte-001 can effec-tively cross the BBB and therefore it may be clinically used against CNS cancer.

\subsection{Molecular bingding modeling between PD-L1 and compounds}

To examine the binding ability between PD-L1 and respective small molecules, we performed a $3 \mathrm{~ns}$ molecular dynamic (MD) simulations of PD-L1 bound compound complexes such as PD-L1/Incyte-001, PD-L1/Incyte-011, and PD-L1/BMS-1001. The root mean square deviation (RMSD) plot of the complexes (Fig. 5A, 6A, and 7A) re-vealed that PD-L1 protein reached the equilibrium after $3 \mathrm{~ns}$ MD simulation, having fluctuation of approximately $1 \AA$ or $2 \AA$, respectively.

To investigate the amino acids involved in binding, the MM/GBSA decomposition protocol in AmberTools was used to decompose the Gibbs free energy (Fig. 5B, 6B, and 7B). We found that the residues Tyr56, GIn66, Met115, Ala121, Asp122, Tyr123, and Lys124 made favorable binding contributions between PDL1 and Incyte-001 (or Incyte-011, BMS-1001). Importantly, the Lys124 and Glu58 provided a positive energy for the binding of PD-L1 and Incyte-011 (or BMS-1001), explaining the worse binding of Incyte001. Besides, PD-L1/Incyte-011 and PD-L1/BMS-1001 complexes exhibited lower binding free energy $(-70.4386$ and $-76.3274 \mathrm{kcal} / \mathrm{mol}$, respectively) than the PD-L1/Incyte-001 $(-55.1401 \mathrm{kcal} / \mathrm{mol})$, suggesting stronger binding in the latter.

Furthermore, molecular docking and dynamic simulation were performed to compare the different conformations and interactions between PD-L1 and the three compounds, as reported previously [25]. Incyte-001, Incyte-011, and BMS-1001 bind in the pocket at the interface of two PD-L1 monomers (Fig. 5C, 6C, and 7C). The binding pocket is formed by several key residues including aGln66, aMet105, aAla121, aAsp122 bTyr56, bMet115, and bAsp122 (Fig. 5D). Also, the exposed benzene ring of the biphenyl group makes a $\pi-\pi$ interaction and a $\pi$-sigma interaction with bTyr56 and aAsp122, respectively. Besides, the methyl phenyl ring forms $\pi$-alkyl interactions with bMet115 and aAla121. The pyridine ring generates $\pi-$ alkyl interactions with bAla121 and aMet105, while the extended ethanolamine moiety forms two hydrogen bonds with aGIn66 and a salt bridge with bAsp122, respectively. The interactions be-tween PDL1 and Incyte-011 are shown in Fig. 6D. The biphenyl group interacts with aAla121, bMet115, alle54, aMet115, and bAla121 to form $\pi$-alkyl interactions, respectively. The pyridine group is involved in $\pi-\pi$ interactions with aTyr56 and bTyr56 and m-anion interactions with aAsp122 and bAsp122, respectively. The ethan-olamine group forms hydrogen bonds with aArg125, aAsp61, and bAsp122. Figure 7D depicts the binding site composed of aGIn66, aMet115 aAla121, aAsp122, aTyr123, aLys124, aArg125, blle54, bGIn66, bVal68, bMet115, and bAla121 residues. The inter-actions between PD-L1 and the other two compounds were almost similar. Interest-ingly, in addition to these, the benzonitrile portion of the pocket 
interacts with aArg113, aTyr123, aArg125, and bAsn63. Especially, the $p-\pi$ interaction with the aArg125 may be the reason for increased potency.

Briefly, this part of the work offers a structural insight to explain the difference in the binding activity of monomers, dimers, and the different chemical skeleton com-pound with PD-L1. Interestingly, the binding type and free energy of BMS-1001 can strongly support the best activity of inhibition for PD-1/PD-L1.

\section{Conclusion}

The immune checkpoint proteins PD-1/PD-L1 are the key proteins affecting the T cell function, which also play a crucial role for tumor immunotherapy. We employed a series of biological tests to estimate the inhibitory activities of the three PD-L1 inhibi-tors: Incyte-001, Incyte-011 and BMS-1001. In the HTRF assay, all three compounds showed great efficacies and inhibited PD-1/PD-L1 interactions in the nanomolar range, in which BMS-1001 exhibited the highest activity $\left(\mathrm{IC}_{50}=0.09 \mathrm{nM}\right)$. And the dimer Incyte-011 $\left(\mathrm{IC}_{50}=5.293 \mathrm{nM}\right)$ is two-fold more potent than the monomer Incyte-001 $\left(\mathrm{IC}_{50}=11 \mathrm{nM}\right)$, which is consistent with the previous report [20]. Subsequent molecular dock-ing indicated that additional interactions of BMS-1001, such as a hydrogen bond with the aArg125, may account for this result.

Inhibition of PD-1/PD-L1 causes the activation of T cell function such as the pro-duction of IFN-Y. Therefore, an IFN-y production assay was performed in our study. We found only Incyte-011 $(1 \mu \mathrm{M})$ increased the level of IFN- $y$ dose-dependently, with a value of $200 \mathrm{pg} / \mathrm{mL}$ at $1 \mu \mathrm{M}$ (the maximum dose). And in the cytotoxicity assay, In-cyte-001 displayed the highest cytotoxicity $\left(\mathrm{EC}_{50}=1.635 \mu \mathrm{M}\right)$ against the A549 cells comparing with other two compounds. The results suggested that the dimer Incyte-011 has more anti-tumor activity and less cytotoxicity than the monomer molecular In-cyte-001.

For exploring the potent of CNS tumors treatment, we assessed the pharmacoki-netic (PK) properties and brain-blood barrier (BBB) permeability of the three com-pounds. In our study, Incyte-001 reached a Cmax of $4000 \mathrm{ng} / \mathrm{mL}$ in the brain and a Cmax $<1000 \mathrm{ng} / \mathrm{mL}$ in the blood, while Incyte-011 and BMS-1001 both had lower Cmax in the brain and higher Cmax in the plasma, suggesting that the monomer mo-lecular Incyte-001 has a good BBB permeability and its concentration in brain is higher. This could be related to better endocytosis [26]; however, it demands further validation. Besides, having a lipophilic structure may help the monomers to easily penetrate the BBB.

Overall, compared with the monomers (Incyte-001), the skeleton of the dimers (Incyte-011) offers high inhibitory activity which suggests that a dimeric structure of BMS-1001 may have even better efficacy. Interestingly, only Incyte-011 increased the IFN-y production obviously. And Incyte-001, which is inferior to Incyte-011 and BMS-1001 in the above aspects, had a good BBB permeability. Our work have suggest-ed that the dimeric structure of small-molecule PD-L1 inhibitors have higher inhibito-ry activity and Incyte001 may have great clinical potential against CNS tumors, which set the basis for further improvement during the drug design for different tumor treatment. 


\section{Experimental}

\section{Chemistry}

General chemistry. All reagents and solvents were obtained directly from the suppliers and were used without further purification. The $1 \mathrm{H}$ NMR spectra were recorded using a Bruker AVANCE III spectrometer in the DMSO- $d_{6}$ solution, with tetramethylsilane (TMS) as the internal standard. Chemical shift values are reported in ppm. The three com-pounds were synthesized according to the corresponding patents (WO2017106634A1, WO2018119221A1, WO2015160641A2) and the procedures are available in the supporting information.

\section{Homogeneous Time Resolved Fluorescence (HTRF)}

The compounds were sequentially diluted following a concentration gradient. In a 96-well plate, $2 \mu \mathrm{L}$ of the target compounds dilution was mixed with $4 \mu \mathrm{L}$ of Tag 1-PD-L1 protein, and $4 \mu \mathrm{L}$ of Tag 2-PD-1 protein, successively. The mixtures were in-cubated for 15 minutes at room temperature (RT). Then the mixture of $10 \mu \mathrm{L}$ an-ti-Tag1-Eu3 + and anti-Tag2-XL665 were added, and the plate was sealed to incubate for $2 \mathrm{~h}$ at RT in the dark. Finally, the fluorescence signal was detected at $665 \mathrm{~nm}$ and $620 \mathrm{~nm}$. The ELISA data and IC50 values were calculated using Graphpad 7.0 software.

\section{In vitro estimation of IFN-y production}

The Hep3B-OS8-hPDL1 cells were treated with Mitomycin C for $1.5 \mathrm{~h}$ and washed with PBS thrice. The cells $(50,000$ cells/well) were added to a 96-well plate. After $2 \mathrm{~h}$, the cells were treated with different concentrations of the respective compounds (100 $\mu \mathrm{L} \mathrm{hPD-L1}$ and $1 \mu \mathrm{L}$ compounds). After another $4 \mathrm{~h}$, the $\mathrm{CD} 3+\mathrm{T}$ cells were extracted, counted, and added to the 96-well plates. Then, the compounds were added and co-cultured at $37^{\circ} \mathrm{C}$. After $36 \mathrm{~h}$, the supernatants were collected to estimate the levels of IFN- $\gamma$. The result was treated with Graphpad software and the statistical analysis was made by t-Test.

\section{In vitrocell-proliferation assay}

The cytotoxicity was detected with the CCK8 assay. The A549 cells were cultured in 96-well plates for 24 $\mathrm{h}$. The compounds were sequentially diluted and was mixed with $0.1 \%$ DMSO in total $100 \mu \mathrm{L}$ of medium. Then the solutions was added and co-cultured for 2 days. The $10 \mu \mathrm{L}$ solution of CCK8 was added and cocultured for $4 \mathrm{~h}$. Then the fluorescence signal at $450 \mathrm{~nm}$ was tested by a microplate reader and the EC50 values were calculated using Graphpad 7.0 software.

\section{In vivothe brain and plasma distribution of compounds}

All animal experiments were performed following the guidelines of Zhejiang University Laboratory Animal Center. The BALB/c male mice were obtained from the Zhejiang Academy of Medical Sciences. The mice venous blood $(100 \mu \mathrm{L})$ and brain tis-sue $(100 \mu \mathrm{L})$ samples were collected at $0,0.083,0.25,0.5,1,2,4$, and 
$8 \mathrm{~h}$ after intrave-nous injection of the test compounds. The plasma and brain tissue homogenates were obtained by centrifugation and stored at $-20^{\circ} \mathrm{C}$ till further use.

\section{Molecular Docking}

The crystal structure (PDB ID: 5NIU) was obtained from http://www.rcsb.org/ and treated using Schrödinger Procedures such as residual repair, hydrogen optimization, water removal, and energy minimization were performed with Protein Preparation Wizard of Schrödinger. The LigPrep module with OPLS3e force field was used to ion-ize and minimize the ligands. The preprocessed proteins and ligands were docked in the Ligand Docking module.

\section{Molecular Dynamics (MD) Simulation}

The molecular dynamics (MD) simulations were carried out using AmberTools. Firstly, the system was solvated, neutralized, and relaxed to avoid possible space colli-sion. Each part was then heated and maintained at $300 \mathrm{~K}$ with a time step of $2 \mathrm{fs}$ using long-distance static electricity. The cut-off value was adjusted to 8.0 A to deal with space interaction. Each part was subjected to a 3 ns MD simulation.

\section{Declarations}

\section{Acknowledgements}

This research acknowledges the support of the Natural Science Foundation of Zhejiang Province (LQ19H090013).

\section{Conflict of Interest}

The authors declare no conflict of interest.

\section{References}

1 Berndt JD, Gough NR. 2013: Signaling Breakthroughs of the Year. Sci Signal. 2014, 7 (307). http://doi: 10.1126/scisignal.aam5681.

2 Messenheimer DJ, Jensen SM, Afentoulis ME, Wegmann KW, Feng, ZP, Friedman DJ, Gough MJ, Urba WJ, Fox BA. Timing of PD-1 Blockade Is Critical to Effective Combination Immunotherapy with Anti-OX40. Clin Cancer Res. 2017, 23 (20), 6165-6177. http://doi: 10.1158/1078-0432.Ccr-16-2677.

3 Iwai Y, Hamanishi J, Chamoto K, Honjo T. Cancer immunotherapies targeting the PD-1 signaling pathway. J Biomed Sci. 2017, 24. http://doi: 10.1186/s12929-017-0329-9.

4 Salmaninejad A, Valilou SF, Shabgah AG, Aslani S, Alimardani M, Pasdar A, Sahebkar A. PD-1/PD-L1 pathway: Basic biology and role in cancer immunotherapy. J Cell Physiol. 2019, 234 (10), 16824-16837. http://doi: 10.1002/jcp.28358. 
5 Freeman GJ, Long AJ, Iwai Y, Bourque K, Chernova T, Nishimura H, Fitz LJ, Malenkovich N, Okazaki T, Byrne MC, Horton HF, Fouser L, Carter L, Ling V, Bowman MR, Carreno BM, Collins M, Wood CR, Honjo T. En-gagement of the PD-1 immunoinhibitory receptor by a novel B7 family member leads to negative regulation of lymphocyte activation. J Exp Med. 2000, 192 (7), 1027-1034. http://doi:

10.1084/jem.192.7.1027.

6 Agata Y, Kawasaki A, Nishimura H, Ishida Y, Tsubata T, Yagita H, Honjo T. Expression of the PD-1 antigen on the surface of stimulated mouse T and B lymphocytes. Int Immunol. 1996, 8 (5), 765-772.

http://doi: 10.1093/intimm/8.5.765.

7 Dong HD, Strome SE, Salomao DR, Tamura H, Hirano F, Flies DB, Roche PC, Lu J, Zhu GF, Tamada K, Lennon VA, Celis E, Chen LP. Tumor-associated B7-H1 promotes T-cell apoptosis: A potential mechanism of immune evasion. Nat Med. 2002, 8 (8), 793-800. http://doi: 10.1038/nm730.

8 Flies DB, Sandler BJ, Sznol M, Chen L. Blockade of the B7-H1/PD-1 pathway for cancer immunotherapy. Yale J Biol Med. 2011;84(4):409-21.

9 Hematology/Oncology (Cancer) Approvals \& Safety Notifications. Available from:

https://www.fda.gov/drugs/resources-information-approved-drugs/hematologyoncology-cancerapprovals-safety-notifications.

10 Yan Y, Zhang L, Zuo Y, Qian H, Liu C. Immune Checkpoint Blockade in Cancer Immunotherapy: Mechanisms, Clinical Outcomes, and Safety Profiles of PD-1/PD-L1 Inhibitors. Arch Immunol Ther Exp. (Warsz). 2020;68(6):36. http://doi: 10.1007/s00005-020-00601-6

11 Hoos A. Development of immuno-oncology drugs - from CTLA4 to PD1 to the next generations. Nat Rev Drug Discov. 2016;15(4):235-47.

http://doi: 10.1038/nrd.2015.35

12 Lin X, Lu X, Luo G, Xiang H. Progress in PD-1/PD-L1 pathway inhibitors: From biomacromolecules to small molecules. Eur J Med Chem. 2020;186:111876. http://doi: 10.1016/j.ejmech.2019.111876

13 Postow MA. Managing immune checkpoint-blocking antibody side effects. Am Soc Clin Oncol Educ Book. 2015:76-83.

http://doi: 10.14694/EdBook_AM.2015.35.76

14 Tan SG, Zhang CWH, Gao GF. Seeing is believing: anti-PD-1/PD-L1 monoclonal antibodies in action for checkpoint blockade tumor immunotherapy. Signal Transduct Tar. 2016, 1. http://doi:

10.1038/sigtrans.2016.29. 
15 Zhao JF, Chen AX, Gartrell RD, Silverman AM, Aparicio L, Chu T, Bordbar D, Shan D, Samanamud J, Mahajan A, Filip I, Orenbuch R, Goetz M, Yamaguchi JT, Cloney M, Horbinski C, Lukas RV, Raizer J, Rae Al, Yuan JZ, Canoll P, Bruce JN, Saenger YM, Sims P, Iwamoto FM, Sonabend AM, Rabadan R. Immune and genomic correlates of re-sponse to anti-PD-1 immunotherapy in glioblastoma (vol 25, pg 462, 2019). Nat Med. 2019, 25 (6), 1022-1022. http://doi: 10.1038/s41591-019-0449-8.

16 Guzik K, Tomala M, Muszak D, Konieczny M, Hec A, Blaszkiewicz U, Pustula M, Butera R, Domling A, Holak TA. Development of the Inhibitors that Target the PD-1/PD-L1 Interaction-A Brief Look at Progress on Small Molecules, Peptides and Macrocycles. Molecules. 2019, 24 (11).

http://doi: 10.3390/molecules24112071.

17 Wang T, Wu X, Guo C, Zhang K, Xu J, Li Z. et al. Development of Inhibitors of the Programmed Cell Death-1/Programmed Cell Death-Ligand 1 Signaling Pathway. J Med Chem. 2019;62(4):1715-30.

http://doi: 10.1021/acs.jmedchem.8b00990

18 Chen T, Li Q, Liu Z, Chen Y, Feng F, Sun H. Peptide-based and small synthetic molecule inhibitors on PD-1/PD-L1 pathway: A new choice for immunotherapy? Eur J Med Chem. 2019;161:378-98. http://doi: 10.1016/j.ejmech.2018.10.044

19 Wu Q, Jiang L, Li SC, He QJ, Yang B, Cao J. Small molecule inhibitors targeting the PD-1/PD-L1 signaling pathway. Acta Pharmacol Sin. 2021;42(1):1-9. http://doi: 10.1038/s41401-020-0366-x

20 Basu S, Yang J, Xu B, Magiera-Mularz K, Skalniak L, Musielak B, Kholodovych V, Holak TA, Hu L. Design, Synthesis, Evaluation, and Structural Studies of C2-Symmetric Small Molecule Inhibitors of Programmed Cell Death-1/Programmed Death-Ligand 1 Protein-Protein Interaction. J Med Chem. 2019, 62 (15), 7250-7263. http://doi: 10.1021/acs.jmedchem.9b00795.

21 Wu L, Yu Z, Zhang F, Yao W. N-PHENYL-PYRIDINE-2-CARBOXAMIDE DERIVATIVES AND THEIR USE AS PD-1/PD-L1 PROTEIN/PROTEIN INTERACTION MODULATORS. WO2017106634A1. 2017.

22 Wu L, Yu Z, Zhang F, Yao W. PYRIDINE DERIVATIVES AS IMMUNOMODULATORS. WO2018119221A1. 2018.

23 Chupak LS, Ding M, Martin SW, Zheng X, Hewawasam P, Connolly TP, Xu N, Yeung KS, Zhu J, Langley DR, TENNEY DJ, Scola PM. COMPOUNDS USEFUL AS IMMUNOMODULATORS. WO2015160641A2. 2015, October 22.

24 Qian JW, Wang C, Wang B, Yang J, Wang YD, Luo FF, Xu JY, Zhao CJ, Liu RH, Chu YW. The IFNgamma/PD-L1 axis between T cells and tumor microenvironment: hints for glioma anti-PD-1/PD-L1 therapy. J Neuroinflamm. 2018, 15. http://doi: 10.1186/s12974-018-1330-2. 
25 Zak KM, Grudnik P, Guzik K, Zieba BJ, Musielak B, Dömling A, Dubin G, Holak TA. Structural basis for small molecule targeting of the programmed death ligand 1 (PD-L1). Oncotarget. 2016, May 24;7(21):30323-35. http://doi: 10.18632/oncotarget.8730.

26 Villaseor R, Lampe J, Schwaninger M, Collin L. Intracellular transport and regulation of transcytosis across the blood-brain barrier. Cell Mol Life Sci. 2019, 76(6).

\section{Figures}

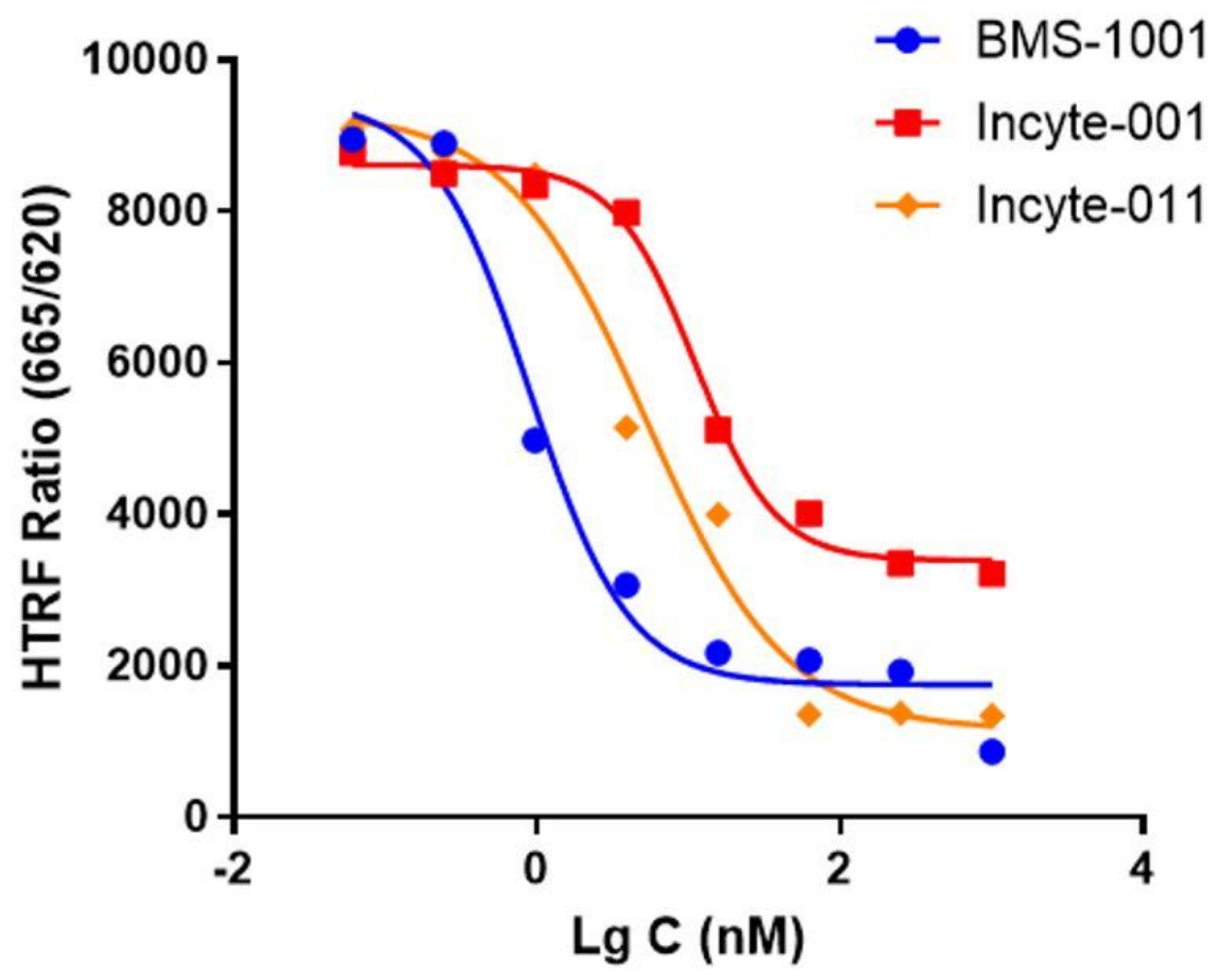

Figure 1

Activities of compound Incyte-001 (red); Incyte-011 (orange); BMS-1001 (blue) in HTRF assay. 


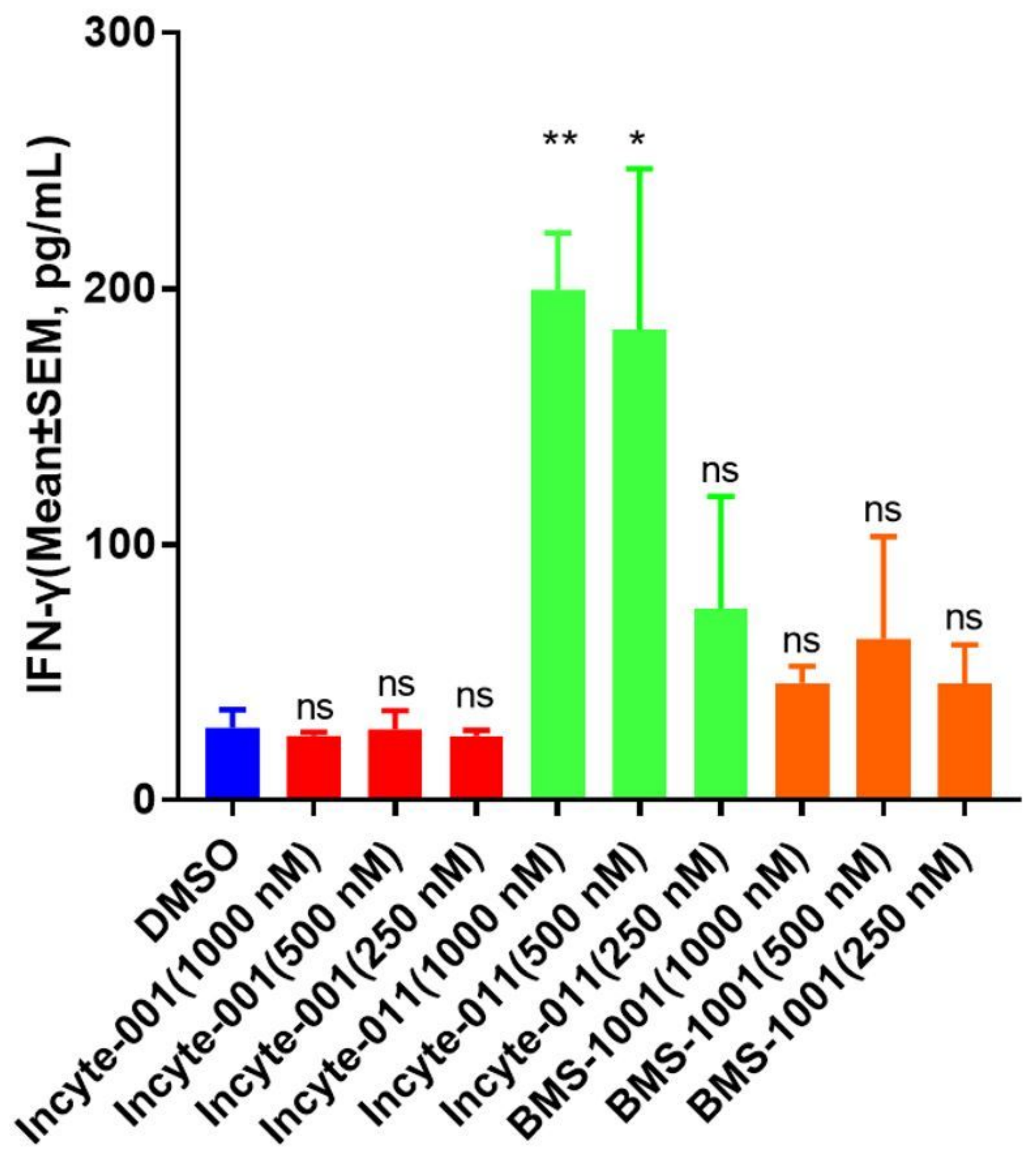

Figure 2

Activity of Incyte-011 and Atezolizumab on IFN-y production. Each group was compared with DMSO group. ${ }^{*} \mathrm{p}<0.05,{ }^{\star *} \mathrm{p}<0.01$ and $\mathrm{ns}=$ no significance. 


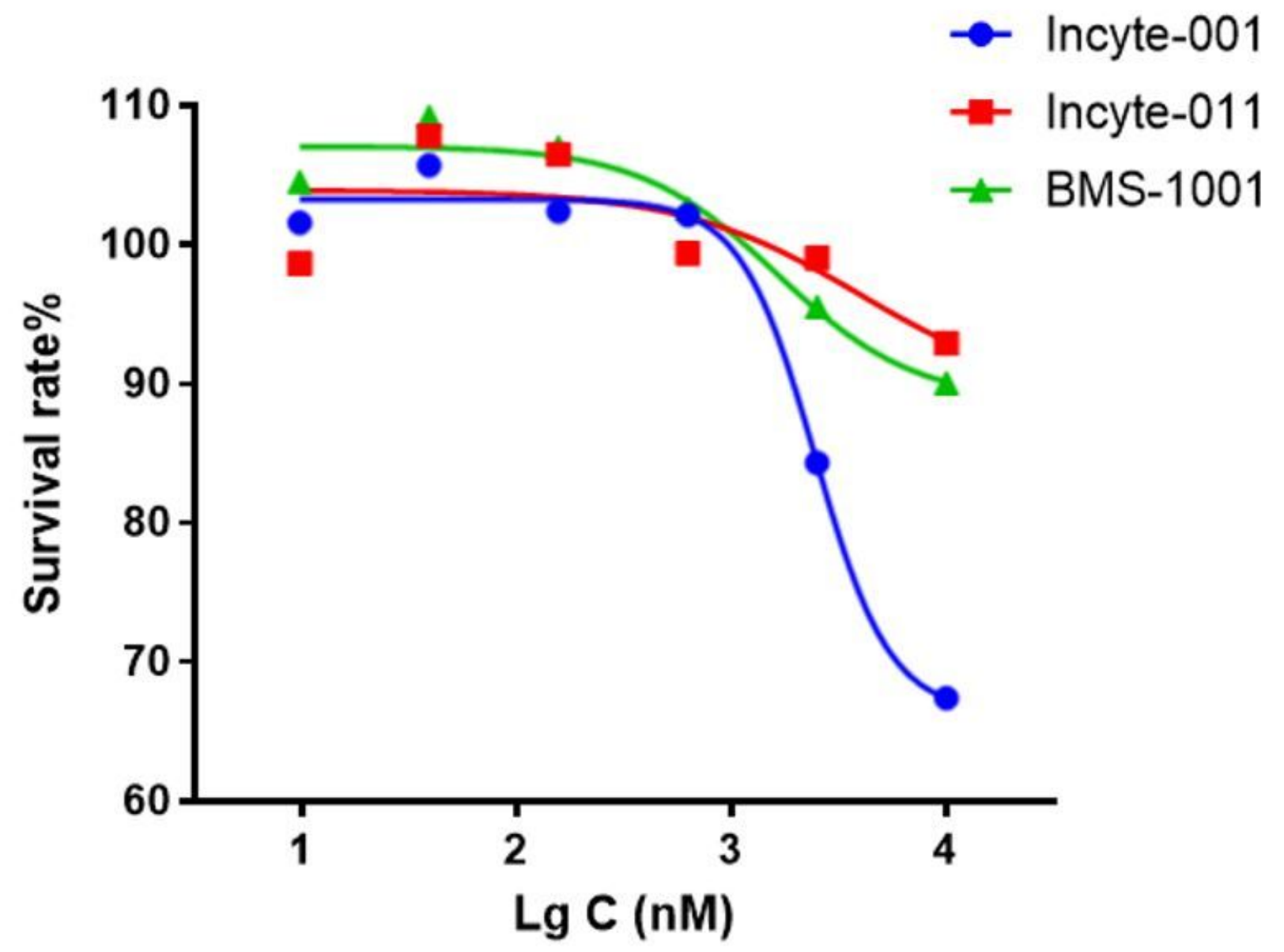

Figure 3

Cytotoxicity of compound Incyte-001, Incyte-011 and BMS-1001 on A549 cell. 


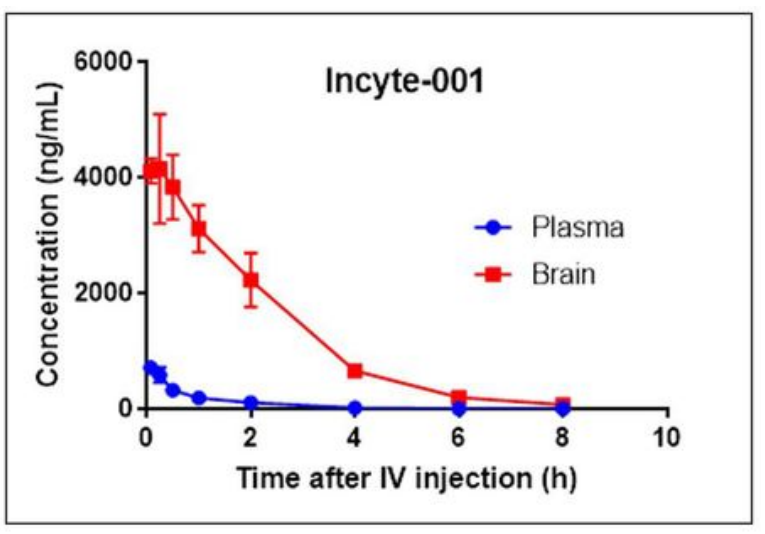

(A)

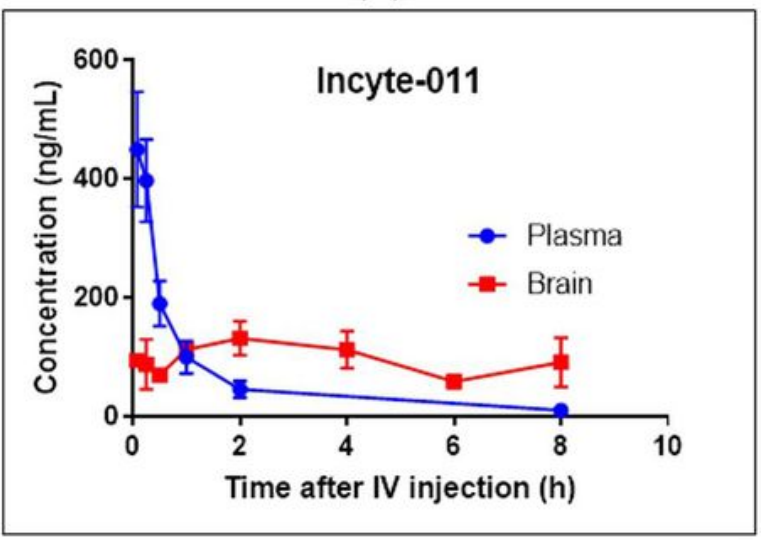

(B)

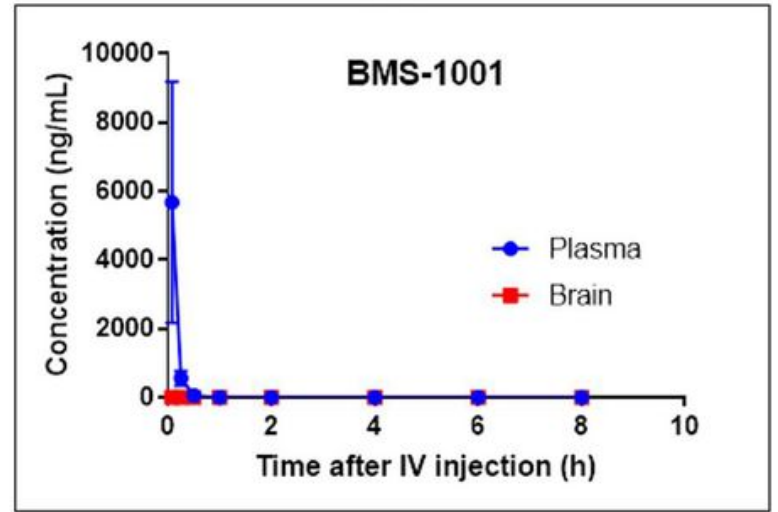

(C)

\section{Figure 4}

Brain and plasma distribution of compounds in mice: (A) Incyte-001; (B) Incyte-011; (C) BMS-1001. 


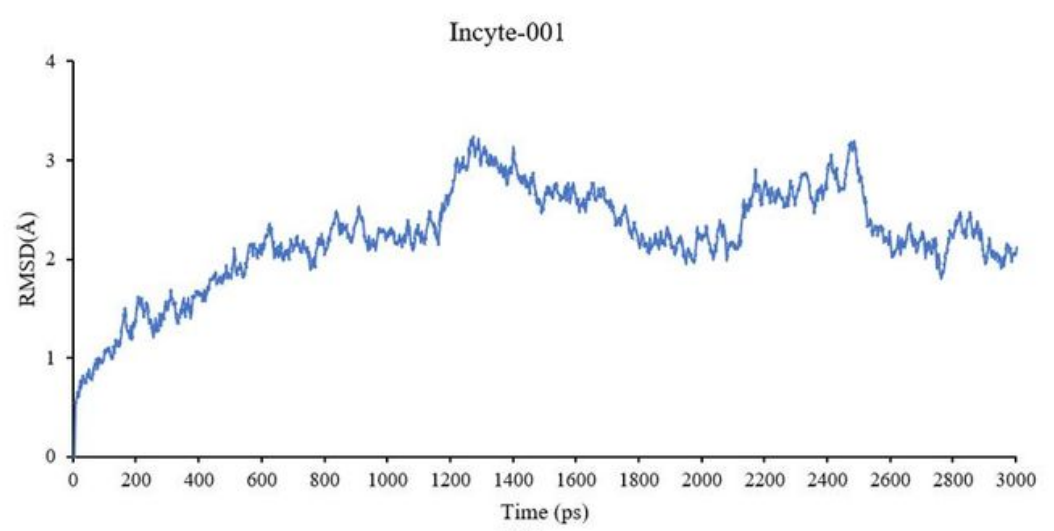

(A)

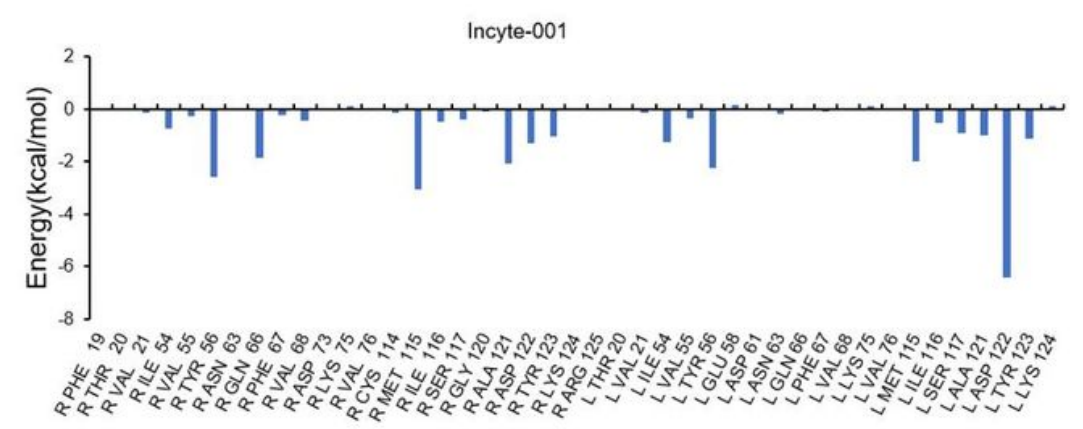

(B)

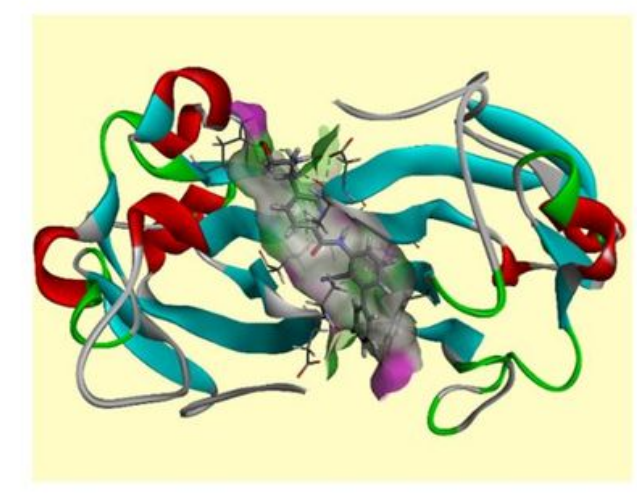

(C)

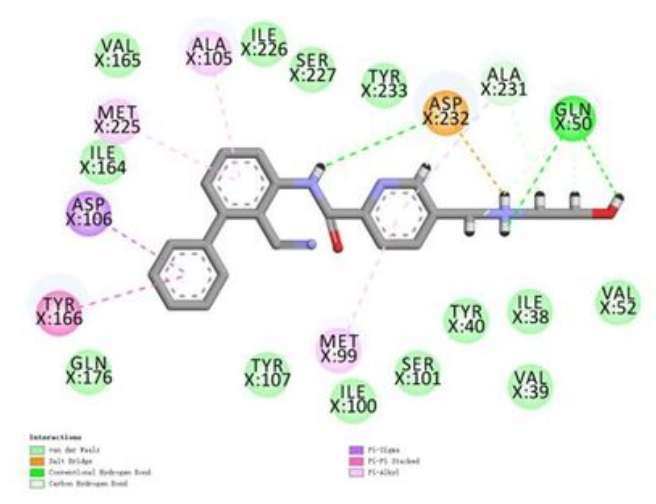

(D)

\section{Figure 5}

Interactions between Incyte-001 and PD-L1. The RMSD of protein PD-L1 (A) and free energy decomposition (B) of PD-L1 and Incyte-001 for a 3ns MD simulation. (C) Molecular docking of Incyte-001 and PD-L1. (D) 2D interactions between Incyte-001 and PD-L1. 


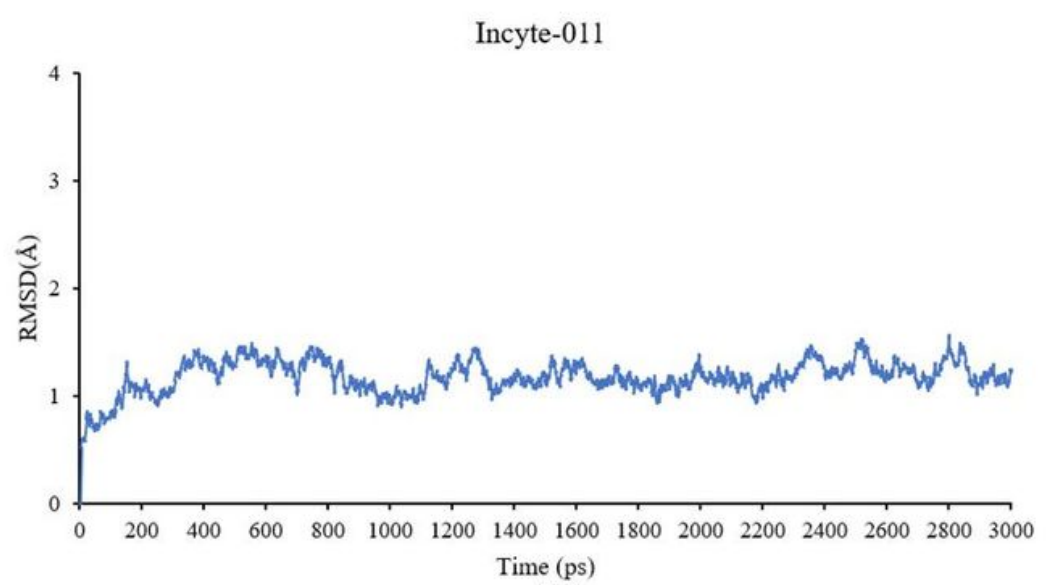

(A)

Incyte-011

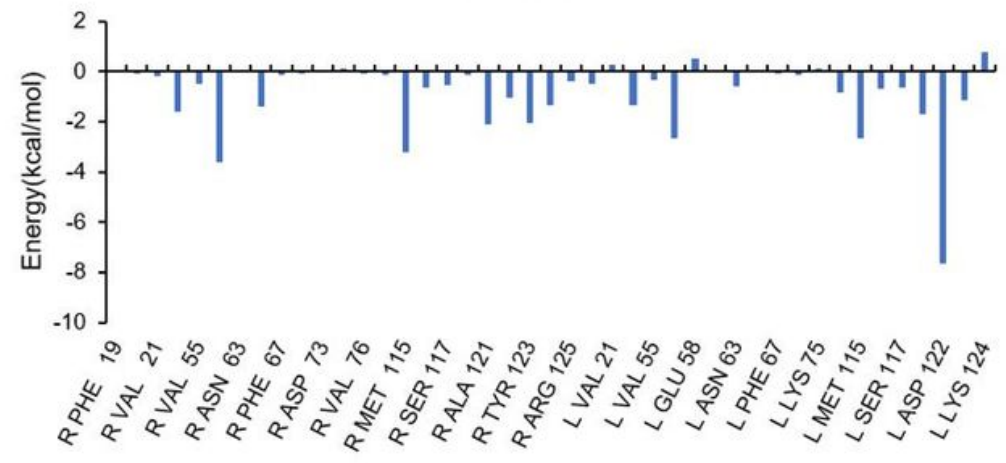

(B)

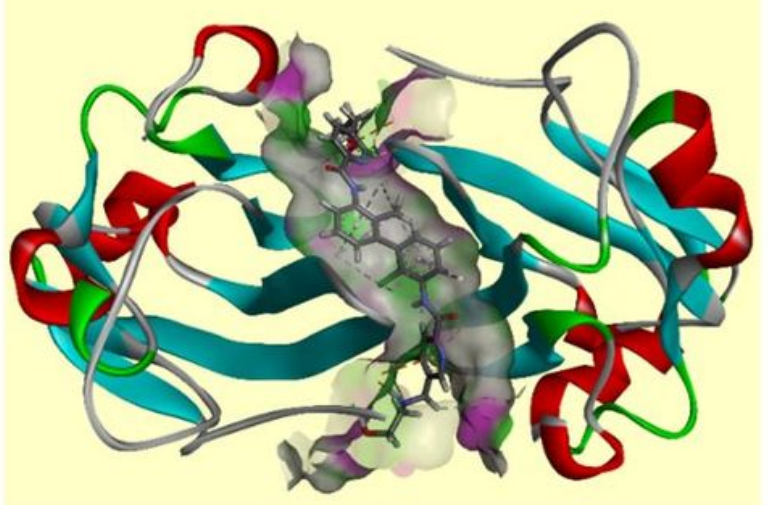

(C)

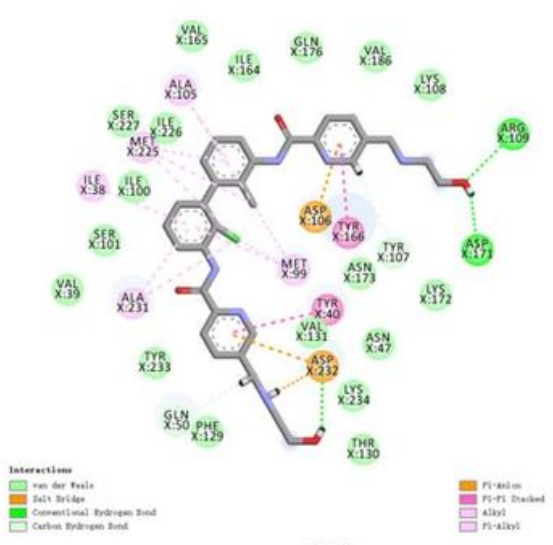

(D)

Figure 6

Interactions between Incyte-011 and PD-L1. The RMSD of protein PD-L1 (A) and free energy decomposition (B) of PD-L1 and Incyte-001 for a 3ns MD simulation. (C) Molecular docking of Incyte-001 and PD-L1. (D) 2D interactions between Incyte-001 and PD-L1. 


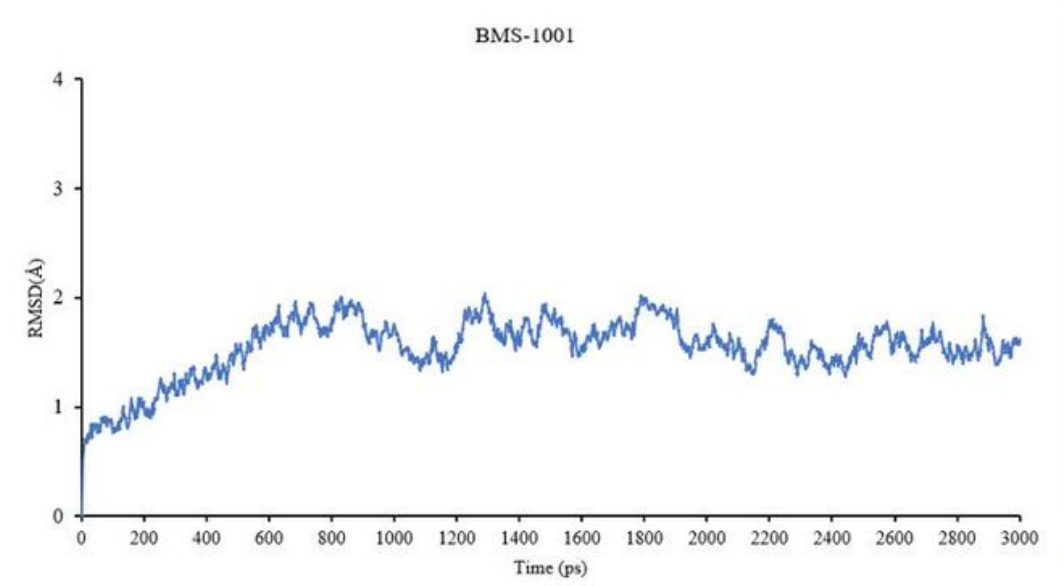

(A)

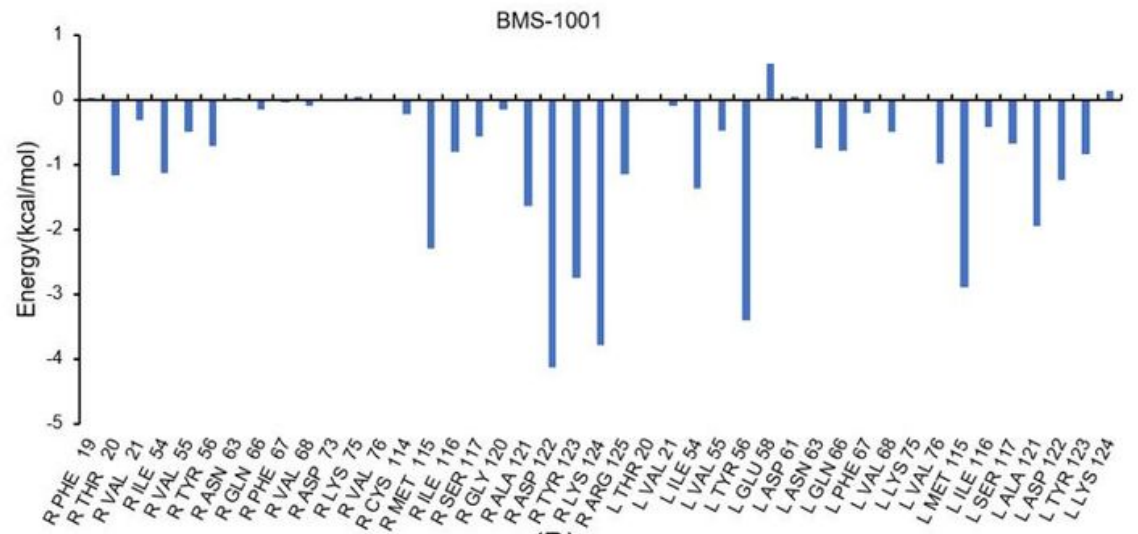

(B)

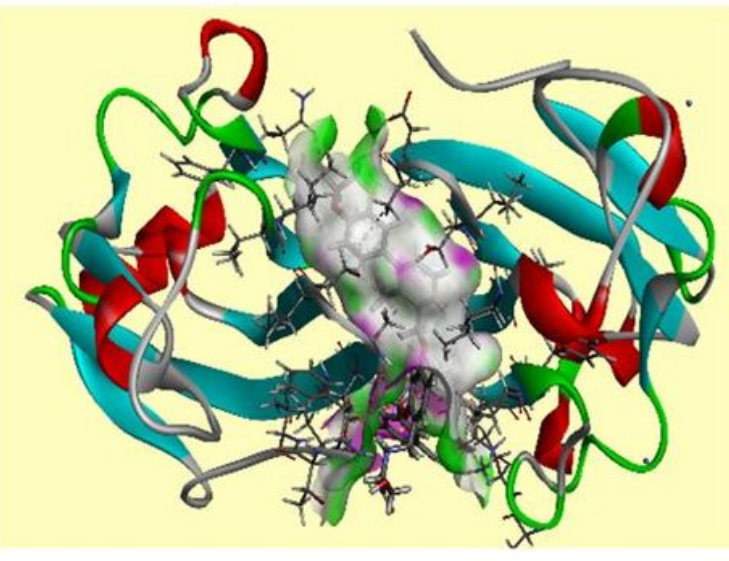

(C)

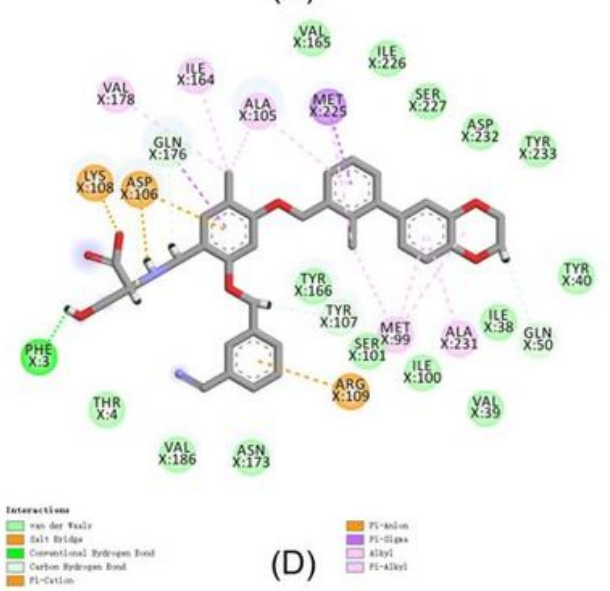

Figure 7

Interactions between BMS-1001 and PD-L1. The RMSD of protein PD-L1 (A) and free energy decomposition (B) of PD-L1 and Incyte-001 for a 3ns MD simulation. (C) Molecular docking of Incyte-001 and PD-L1. (D) 2D interactions between Incyte-001 and PD-L1.

\section{Supplementary Files}

This is a list of supplementary files associated with this preprint. Click to download.

- scheme1.jpg

- scheme2.jpg

- scheme3.jpg

- scheme4.jpg

- Graphicsabstract.jpg 